\title{
Synthesis, modification and use of lignified bamboo isolate for the renovation of crystal violet dye effluent
}

\author{
C. O. Aniagor ${ }^{1}$ (D) M. C. Menkiti ${ }^{1,2}$
}

Received: 15 February 2019 / Accepted: 23 April 2019 / Published online: 2 May 2019

(c) The Author(s) 2019

\begin{abstract}
Bamboo-based lignin (LBM) was synthesized from a simulated effluent of modified textile manufacturing process for bamboo fabrics. The efficacy of LBM modified with $\mathrm{Al}^{3+}(\mathrm{Al}-\mathrm{LBM})$ and $\mathrm{Mn}^{2+}(\mathrm{Mn}-\mathrm{LBM})$ for the remediation of crystal violet dye polluted wastewater was evaluated. Instrumental characterization of the adsorbents via Fourier transform infrared spectroscopy and scanning electron microscopy was conducted. Probable process mechanisms were postulated. The Langmuir, Sip and Freundlich isotherms were the best fit model for LBM, Al-LBM and Mn-LBM, respectively. Among the interactively competing mechanisms (confirmed by $k$-value and intra-particle diffusion model), the pseudofirst-order kinetic model predominated. Optimum temperature and contact time were $343 \mathrm{~K}$ and $30 \mathrm{~min}$, respectively. The adsorption process was (based on average data) spontaneous $\left(\Delta G=-1198.69 \mathrm{~kJ} \mathrm{~mol}^{-1}\right)$, endothermic $\left(\Delta H=+86.85 \mathrm{~kJ} \mathrm{~mol}^{-1}\right)$ and efficient $(+98.11 \%)$.
\end{abstract}

Keywords Adsorption · Bamboo $\cdot$ Lignin $\cdot$ Crystal violet dye $\cdot$ Isotherm

\section{Introduction}

Pharmaceutical, plastic, textile and food processing industries heavily employ synthetic dyes as coloration ingredients for their products (Vargas et al. 2012). Dyes are used to make the products more attractive to consumers. Although some dyes inculcate antibacterial, antifungal, and anthelmintic properties; they have no nutritional values when used as coloration for food and drugs (Vargas et al. 2012). Dyes that contain one or more auxochromic groups (such as amino, methylamino, dimethylamino, or hydroxyl groups) in their structure are considered triarylmethane dye. Such dyes are however mutagenic and

Electronic supplementary material The online version of this article (https://doi.org/10.1007/s13201-019-0962-4) contains supplementary material, which is available to authorized users.

C. O. Aniagor

Aniagor@yahoo.com; co.aniagor@gmail.com

M. C. Menkiti

mc.menkiti@unizik.edu.ng; matthew.menkiti@ttu.edu

1 Chemical Engineering Department, Nnamdi Azikiwe University, Awka, Nigeria

2 Civil and Environmental Engineering Department, Water Resources Center, Texas Tech University, Lubbock, TX, USA carcinogenic when ingested disproportionately by human and other living organisms. Among the triarylmethane dyes, crystal violet (gentian violet) dye (CVD) is important for its use in artificial coloration of textile material (Osol and Hoover 1975). Similarly, CVD is employed (strictly for oral and external use) as antibacterial, antifungal, and anthelmintic medication. According to the report of FOA/ WHO food additive evaluation, it is inappropriate to set an ADI (acceptable daily intake) for crystal violet dye because of its genotoxic and carcinogenic nature. Hence, the risk factors associated with the ingestion of minute quantity of CVD are very enormous. The contamination risk in humans and environment is further heightened by the multi-disciplinary application of CVD. The improper discharge of CVD molecules as constituents of wastewater from process industries into several important water bodies has raised a major environmental concern (Gao et al. 2013; Jaime et al. 2017). Hence, to ensure the integrity of the natural environment, several technologies have been adopted for efficient dye wastewater remediation. They include: coagulation/flocculation (Menkiti et al. 2016), ozonation (Nethaji et al. 2013), photocatalytic degradation (Bitenc et al. 2013; Elghniji et al. 2019), electrocatalytic degradation (Suhadolnik et al. 2016) and adsorption (Menkiti et al. 2018a, b; Ngah et al. 2011). Adsorption process remains one of the most common, reliable and 
useful technique adopted for synthetic dye removal from dye-house effluents (Yu et al. 2013; Kannan et al. 2013; Villarreal et al. 2013). This is because of its flexibility of operation, easy availability of adsorbents and cost-effectiveness (Yu et al. 2013; Kannan et al. 2013; Villarreal et al. 2013).

Bamboo is a perennial plant that contains mainly p-coumaric alcohol resulting in higher concentration of p-hydroxyphenyl alcohol (Chen 2014). Bamboo is a raw material for manufacturing textile fabric in various countries. However, the textile manufacturing processes for bamboo fabrics using alkaline hydrolysis with multi-phase bleaching are not considered sustainable or eco-friendly. This is due to the potential health risk and damages accruing from the discharge of post-processing lignocellulosic residue to the environment (Michael 2007). Thus, it is plausible to recycle these residues to achieve valuable sources of economic activities and also to alleviate the contaminant load on the environment (Ruggiero et al. 2005; Cardoso et al. 2012). Various adsorbents have been used for the isolation of dyes molecules from aqueous solution (Yu et al. 2013; Kannan et al. 2013; Villarreal et al. 2013). Among these adsorbents is lignin which is one of the most abundant organic polymers in plants, just behind cellulose (Chen 2014). Several studies (Zhingang et al. 2017; Yinliang et al. 2016; Adebayo et al. 2014; Menkiti and Aniagor 2017) have reported the existence of various functional groups such as methoxyl, phenolic, carboxyl, aromatic, alcohol, hydroxyl, aldehyde, etc., in lignin. These available functional groups explain lignins' potential in the remediation of dye effluent.

Several publications exist on the application of lignin in dye adsorption processes; study by Yinliang et al. (2016) showed the comparison of lignin obtained from larch and poplar tree for the uptake of methylene blue Dye. Zhingang et al. (2017) evaluated the uptake of methylene blue (MB) from simulated wastewater using Cortaderia selloana flower spikes and its carbon fiber derivative as adsorbents. Adebayo et al. (2014) studied the removal of aqueous Procion Blue MX-R (PB) dye using modified carboxy-methylated lignin (CML). Studies by Menkiti and Aniagor (2017) reported the efficacy of lignin obtained via the alkaline hydrolysis of palm tree trunk for the uptake of aqueous crystal violet dye.

In the present study, lignin was produced from a simulated effluent of modified textile manufacturing process for bamboo fabrics. The choice of adsorbent was informed by a genuine need toward abating the perennial environmental pollution associated with the production of bamboo fabrics. The lignin (LBM) which was further modified (for an improved adsorptive uptake) with aluminum (Al-LBM) and manganese (Mn-LBM) were used as adsorbents for the removal of aqueous crystal violet (CVD) dye. Different isotherm and kinetic models were fitted to the experimental data, while probable adsorption mechanisms were proposed for the process.

\section{Materials and methods (Supplementary material)}

1. Material collection and preparation

2. Synthesis of adsorbent

3. Characterization of adsorbent

4. Batch adsorption studies

5. Equilibrium models

6. Kinetic models

\section{Results and discussion}

\section{Characterization of adsorbent}

\section{Proximate analysis}

From the LBM, Al-LBM and Mn-LBM surface area values presented in Table S1, it was evident that the respective adsorbents' surface areas were comparable to those obtainable in the literature. In comparison to the unmodified adsorbent (LBM), the chemically modified adsorbents (Al-LBM and Mn-LBM) were characterized by larger surface area. Meanwhile, the occurrence of structural reformation on the adsorbent sequel to chemical modification could be the probable cause of the improved Al-LBM and Mn-LBM surface areas (Yin et al. 2012). For Al-LBM, the chemical modifier $\left(\mathrm{Al}_{2} \mathrm{O}_{3}\right)$ being an amphoteric oxide somewhat behaves as both an acid and base in the presence of water molecules as shown in Eqs. 1 and 2, respectively;

$\mathrm{Al}_{2} \mathrm{O}_{3}+\mathrm{OH}^{-} \rightarrow 2 \mathrm{AlO}_{2}^{-}+\mathrm{H}^{+}$

$\mathrm{Al}_{2} \mathrm{O}_{3}+6 \mathrm{H}^{+} \rightarrow 2 \mathrm{Al}^{3+}+3 \mathrm{H}_{2} \mathrm{O}$

Hence, the interactions of $\mathrm{Al}_{2} \mathrm{O}_{3}$ with the adsorbent pores promote reactions which could lead to the widening of those pores and subsequent development of more pores. Similarly for Mn-LBM, the semiconductor particles originating from $\mathrm{MnO}_{2}$ assist in the surface area enhancement and also generate a large number of surface hydroxyl radicals (Ameta et al. 2010). These radicals are useful as primary oxidants for degrading CVD.

Significant decrease in the moisture and volatile content values was also observed for Al-LBM and Mn-LBM (chemically modified adsorbents) when compared to those of LBM (unmodified adsorbent). The post-modification oven drying of Al-LBM and Mn-LBM could have resulted in the loss of some of their inherent volatile matters, hence the observed reduction. The proximate 
analyses result indicates clear differences in certain physico-chemical properties of unmodified adsorbent (LBM) and chemically modified adsorbents (Al-LBM and MnLBM), due to probable effect of chemical modification on the later (Table S1). Similarly, confirmation of lignin as the major constituent of the adsorbents was achieved via biochemical characterization.

\section{Surface chemistry}

The pre-adsorption FTIR spectrum of LBM (Fig S1) shows the presence of several functional groups. The $\mathrm{X}-\mathrm{H}$ stretching region (where ' $\mathrm{X}$ ' represents a non-metallic atom) housing hydroxyl $(\mathrm{O}-\mathrm{H})$, amine $(\mathrm{N}-\mathrm{H})$ or aliphatic $(\mathrm{C}-\mathrm{H})$ stretching vibration occurs within the long bandwidth around 2900-2400 $\mathrm{cm}^{-1}$ (Günter and David 2014; Aniagor and Menkiti 2018). Other important functional groups in existence are aliphatic stretching group, $\mathrm{C}=\mathrm{C}\left(2336-2102 \mathrm{~cm}^{-1}\right)$, carboxylic stretching vibration (1732-1901 $\mathrm{cm}^{-1}$ ), ketone stretching group, $\mathrm{C}=\mathrm{O}$ $\left(1635 \mathrm{~cm}^{-1}\right)$ and aromatic ring of carboxylic anhydrides, $\mathrm{C}=\mathrm{C}\left(1039 \mathrm{~cm}^{-1}\right)$. Consequently upon chemical modification (in the case of AL-LBM and Mn-LBM), the spectra (Fig. S1) were characterized by a decrease, disappearance or widening of some of the peaks. Furthermore, there was the substitution of $\mathrm{C} \equiv \mathrm{C}$ and $\mathrm{C} \equiv \mathrm{N}$ bonds (the most common absorption peaks at $2400-2300 \mathrm{~cm}^{-1}$ region) by $\mathrm{X}-\mathrm{H}$ stretching band (with ' $\mathrm{X}$ ' being a more massive atom, in this case aluminum and manganese). This explains the high intensity peak exhibited by Al-LBM and Mn-LBM samples at $2400-2300 \mathrm{~cm}^{-1}$ (Zhao et al. 2012; Menkiti and Aniagor 2017). Further comparison of the pre- and post-adsorption FTIR spectra depicts the existence of obvious identical peaks, and in some case, peaks with small band shifts of about $2 \mathrm{~cm}^{-1}$. The use of $4 \mathrm{~cm}^{-1}$ band resolution for the entire spectra image could be the probable explanation for such observation.

\section{Surface morphology}

Figure S2a-c presents the SEM images of LBM, Al-LBM and Mn-LBM, respectively. Visual inspection of LBM (unmodified adsorbent) image showed the presence of limited and poorly developed pores, coupled with rough and uneven textural characteristics. However, the chemical activation/modification of LBM into chemically modified adsorbents (Al-LBM and Mn-LBM) positively impacted their respective morphologies, as evidenced in the obvious well-developed pores noticed on Al-LBM and Mn-LBM surfaces. Similarly, Al-LBM and Mn-LBM surfaces were further characterized by increased surface roughness and unevenness when compared to that of LBM. This observation could have stemmed from the structural defect perpetuated on LBM (during to the chemical activation step). Therefore, it could be said that the generation of well-developed porous structure was the hallmark of the physiochemical activation, an attribute which would culminate to increased CVD \% uptake.

\section{Temperature effect on adsorption}

The combined effect of solution temperature and contact time on adsorption efficiency is depicted in Fig. 1. It could be deduced from the plot that an increase in solution temperature (from 303 to $343 \mathrm{~K}$ at optimum time of $30 \mathrm{~min}$ ) led to the appreciation of removal efficiency from 81.02 to $92.25 \%, 83.75$ to $97.05 \%$ and 92.99 to $99.32 \%$ for LBM, Mn-LBM and Al-LBM, respectively. The retardation of the drag forces acting on the diffusing CVD ions due to an increment in molecular kinetic energy (occasioned by the gradual elevation of the solution temperature) could have resulted in the creation and probable enlargement of inherent pores on the adsorbent, thus leading to improved process efficiency (Srivastava et al. 2008). Such observation collaborate the endothermic nature of the present adsorption system. The obtained result is at par with those reported earlier by Menkiti and Aniagor (2017) and Menkiti et al. (2015).
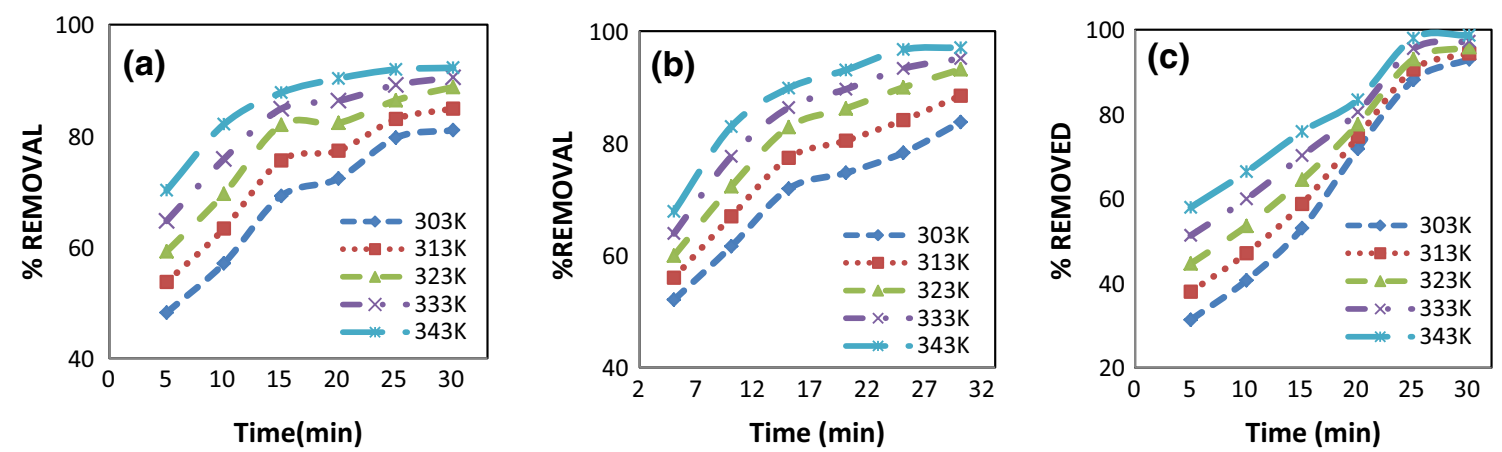

Fig. 1 Effect of solution temperature on CVD adsorption by a LBM, b Mn-LBM, c Al-LBM

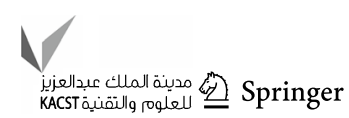


Fig. 2 Fits of the isotherm models for Al-LBM (a, b), Mn$\operatorname{LBM}(\mathbf{c}, \mathbf{d})$ and $\operatorname{LBM}(\mathbf{e}, \mathbf{f})$
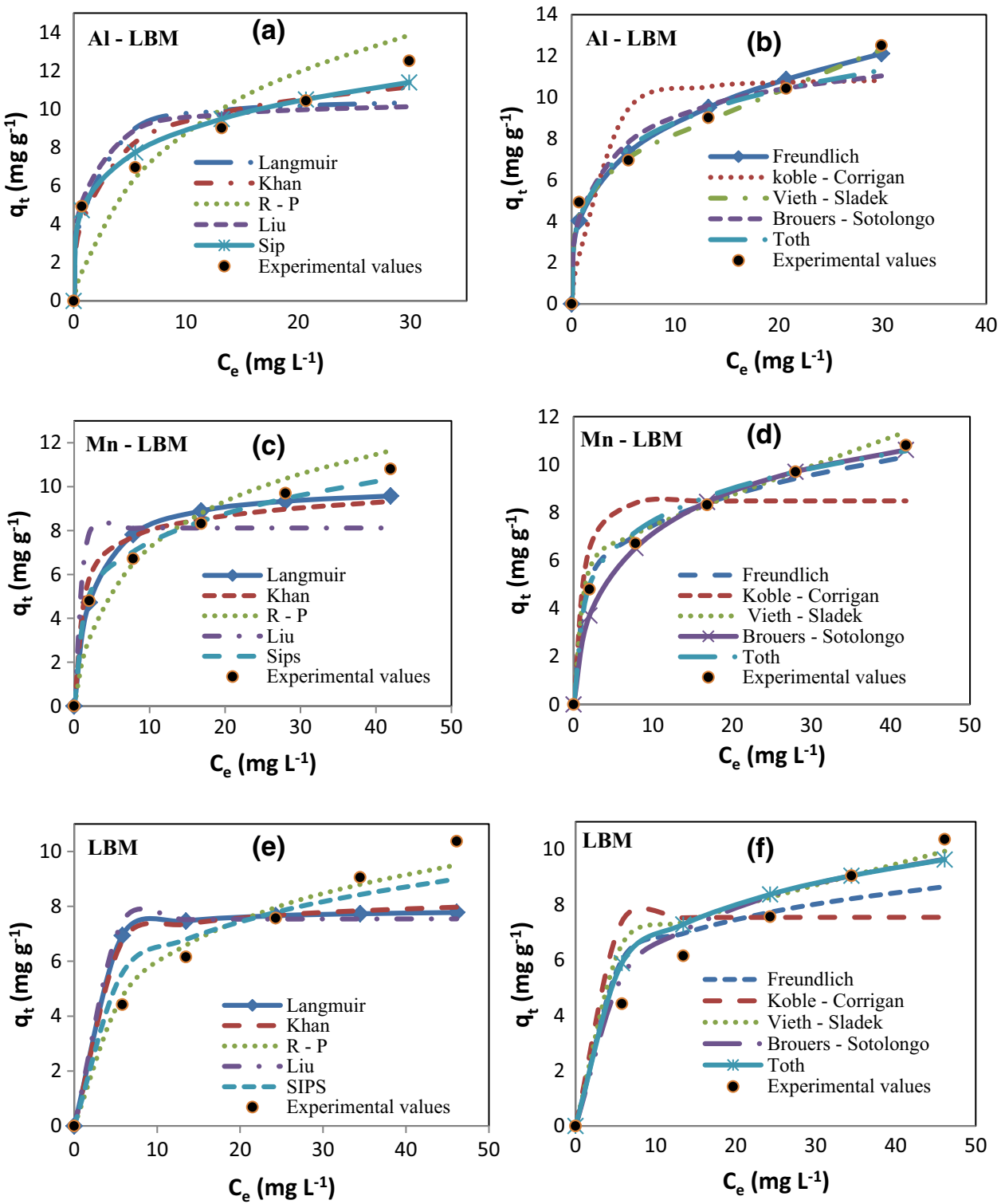

\section{Isotherm study}

Figure 2 presents the isotherm model plot for the respective adsorbents. The value of maximum adsorption capacity $\left(q_{\mathrm{m}}\right)$, correlation coefficient $\left(R^{2}\right)$, normalized standard deviation $\left(F_{\text {error }}\right)$ and the other isotherm parameters are presented in Table S2. For an informed analysis of the Langmuir isotherm, certain analytical conditions (on the basis of separation factor, $R_{\mathrm{L}}$ ) are usually employed to verify how unfavorable $\left(R_{\mathrm{L}}>1\right)$, linear $\left(R_{\mathrm{L}}=1\right)$, favorable $\left(0<R_{\mathrm{L}}<1\right)$, or irreversible $\left(R_{\mathrm{L}}=0\right)$ an adsorption system was. For the studied concentration range $\left(50,100\right.$ and $\left.150 \mathrm{mg} \mathrm{L}^{-1}\right)$, the $R_{\mathrm{L}}$ values ranging from 0.587 to 0.033 (for $\mathrm{Al}-\mathrm{LBM}$ ), 0.532 to 0.0516 (for Mn-LBM) and 0.123 to 0.0174 (for LBM) were obtained. These values attested to the favorability of the adsorption process. The characteristic nature of an adsorption system modeled using Freundlich isotherm could be segregated on the basis of the heterogeneity factor $\left(n_{\mathrm{F}}\right)$, as linear $\left(n_{\mathrm{F}}=1\right)$, a chemical process $\left(n_{\mathrm{F}}<1\right)$, or a physical process $\left(n_{\mathrm{F}}>1\right)$. The $n_{\mathrm{F}} \gg 1$ obtained for this study (Table S2) suggest the favorability of physical adsorption process. However, these frequently used two-parameter isotherm model may not sufficiently elucidate the behavior of the adsorption system under consideration, hence the consideration of other isotherm models (supplementary material). In order to define the best fit isotherm, a normalized standard deviation, $F_{\text {error }}(\%)$ was used (Eq. S10). The error function evaluates the difference between the experimental and predicted isotherm data; hence the lower the $F_{\text {error }}$ value, the better the fit.

The Langmuir model for LBM showed $F_{\text {error }}$ value of $0.575 \%$ which is the lowest value among the studied models. The $F_{\text {error }}$ value of Freundlich (1.043\%) and 
Redlich-Peterson (1.410\%) is relatively low, of about 0.468 and 0.835 -fold higher than that of Langmuir isotherm. The rest of the models showed $F_{\text {error }}$ values in the range of 2.10 and $8.35 \%$ (Table S2). However, based on the assertion that the lower the $F_{\text {error }}$ value the better the fit, it could be concluded that Langmuir model adequately explains CVD uptake by LBM. For Al-LBM, the $F_{\text {error }}$ value of Sip model was $0.318 \%$ (lowest) and is therefore considered the best fit model. Those obtained for Khan $(0.515 \%)$ and Vieth-Sladek $(0.788 \%)$ were relatively low when compared to the other models which showed a large variation in $F_{\text {error }}$ values (between 1.049 and $7.532 \%$ ). The finding indicates the inadequacy of these models to provide good fit for adsorption onto Al-LBM. Regarding Mn-LBM, the Freundlich isotherm showed the lowest $F_{\text {error }}$ value $(0.436 \%)$; hence, it is considered the best fit model. The Brouers-Sotolongo, Toth and Sip models were 0.48-, 0.654- and 0.801-fold higher, respectively, than the $F_{\text {error }}$ value obtained for Freundlich model. Similarly, large $F_{\text {error }}$ value (between 2.585 and $8.159 \%$ ) depicted by the other models showed their inadequacy in modeling adsorption onto Mn-LBM.

The summary of the findings shows that Langmuir, Sip and Freundlich isotherm models was the best model in describing CVD adsorption onto LBM, Al-LBM and MnLBM, respectively.

\section{Kinetic studies}

Four kinetic models, pseudofirst-order (PFO), pseudosecond-order (PSO), Elovich and Avrami models were employed in kinetic data analyses. The basic assumption of PFO and PSO is that adsorption is a pseudo-chemical reaction. The Avrami model evaluates the adsorption rate and fractional kinetic order of the process with respect to
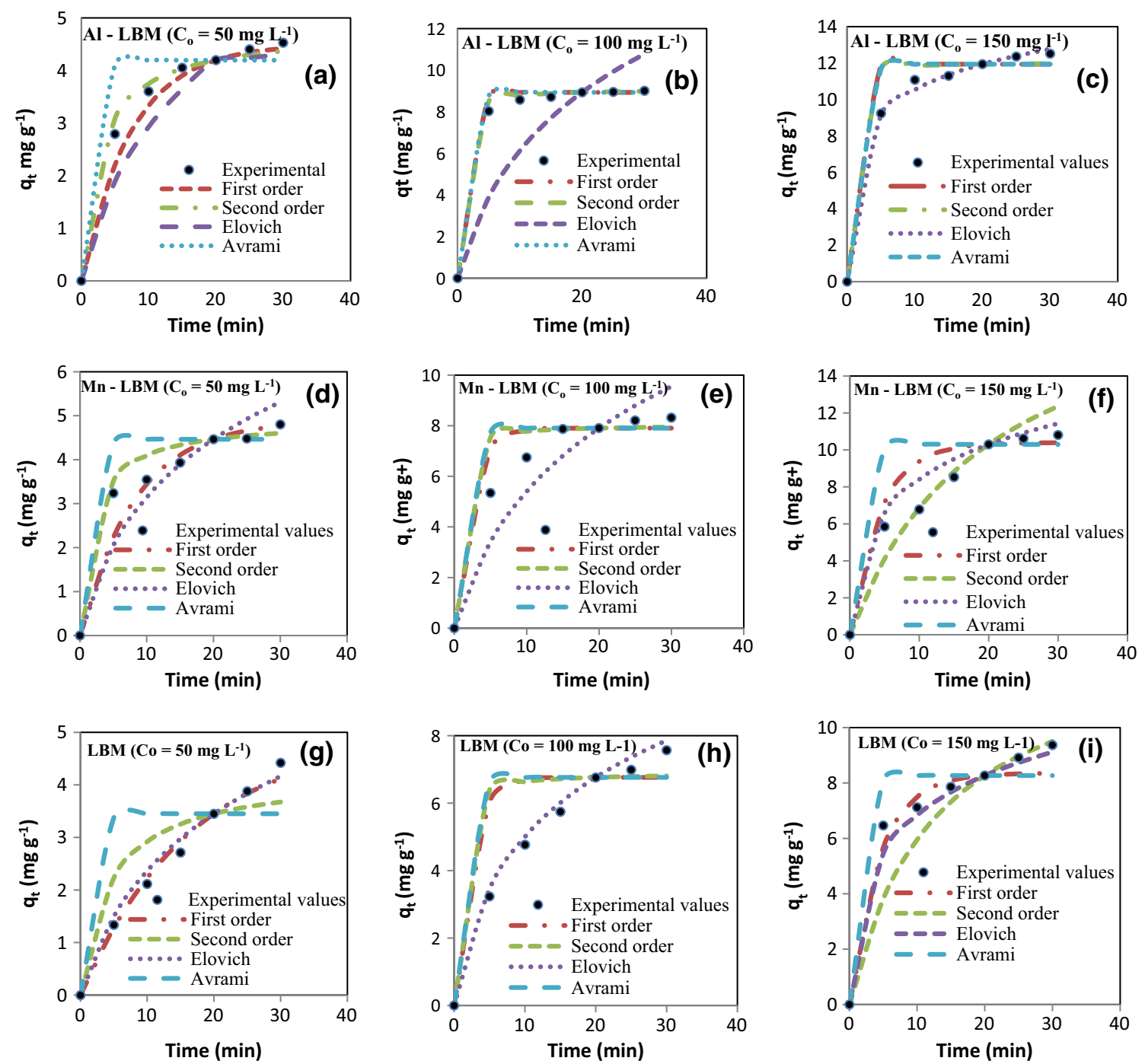

Fig. 3 Fits of the kinetic models at initial concentration of 50, 100 and $150 \mathrm{mg} \mathrm{L}^{-1}$ for Al-LBM (a-c), Mn-LBM (d-f) and LBM (g-i) 
initial concentration and time (Adebayo et al. 2014). Similarly, Elovich model is effectively employed in modeling chemisorption process.

Initial concentrations of 50,100 and $150 \mathrm{mg} \mathrm{L}^{-1}$ were studied for each adsorbent. The experimental data plots as depicted by the various models are presented in Fig. 3 for LBM, Al-LBM and Mn-LBM, respectively. For all the studied models, the values of $q_{\mathrm{e}}, F_{\text {error }}$ and $R^{2}$ and other parameters are presented in Table S3. To make for easy discussion, only the average values of the kinetic study results were considered. The Elovich and Avrami model showed high average $F_{\text {error }}$ values; therefore, these two models were not considered relevant in modeling the studied system. For Al-LBM, Mn-LBM and LBM, the PFO model showed average $F_{\text {error }}$ value of $0.730,1.500$ and $1.629 \%$, respectively, and for PSO model, an average value of $0.854,1.898$ and $1.656 \%$, respectively. This indicates that both models provide good fit for the experimental data. However, PFO was considered the best fit model for the three adsorbents since it showed the lowest $F_{\text {error }}$ value in all cases of adsorbents.

Furthermore, it could be observed that the adsorption capacity $\left(q_{\mathrm{e}}\right)$ and overall rate constant $(k)$ for PFO models (Table S3) increased with increase in initial concentration. Similarly, the initial adsorption rate $\left(h_{\mathrm{o}}\right)$ also varied as the initial adsorbate concentration. According to Oladoja et al. (2008), the $k$-value is a function of the adsorbates' initial concentration; thus, the pseudo-chemical reaction rate constant $k$ as a function of initial adsorbate concentration could be expressed as Eq. 3 (Oladoja et al. 2008);

$K=M C_{o}^{n}$

where $M, C_{o}$ and $n$ are the intercept, initial adsorbate concentration and slope, respectively. When the graph of log $k$ against $\log C_{o}$ was plotted for all adsorbents (Fig. S3), it gave a straight line plot. The introduction of the relevant plot parameters (Table S4) into Eq. 3 will yield an empirical relationship between $k$ and $C_{o}$ and is stated thus;

$K_{\mathrm{LBM}}=-4.323\left[C_{O}\right]^{1.829}$

$K_{\mathrm{Al}-\mathrm{LBM}}=-4.060\left[C_{O}\right]^{1.902}$

$K_{\mathrm{Mn}-\mathrm{LBM}}=-2.896\left[C_{O}\right]^{1.156}$

The observed positive slopes (Table S4) could be attributed to the increment in pseudofirst-order rate constant with an increase in $C_{o}$. Study by Mckay et al. (1985) reported a slope of 0.5 , a confirmation that intra-particle diffusion was the prominent factor in the adsorption process. Hence, the value of $n \gg 0.5$ obtained in this study suggests the influence of other factors on the adsorption process other than intra-particle diffusion. Furthermore, the positive and negative values of intercept and slope, respectively, reported by Oladoja et al. (2008) were ascribed to a decrease in $k$-value with concentration increase. Similarly, the positive and negative values of slope and intercept, respectively, observed in this study could have occurred due to $k$-value increase with increase in initial concentration.

Investigation of the prominent mechanism governing the present adsorption process was ascertained using intraparticle diffusion model (Eq. S23). The plot of $q_{t}$ versus $t^{1 / 2}$ and other relevant parameters obtained from the slope of the plot are presented in Fig. S4 and Table S5, respectively. By visual inspection, it was obvious that the plots were composed of three linear portions, indicative of multiple adsorption mechanisms (Adebayo et al. 2014). The initial linear section depicts the time of dye molecule adherence to the adsorbents' surface, the second portion correlates to the slow intra-particle diffusion process, and the third section represents the inter-porous diffusion period (Adebayo et al. 2014). Generally, the optimum/equilibrium time in any adsorption system (especially those governed by multiple mechanisms) corresponds to the first data point on the last linear portion of the plots. Hence, the equilibrium time of 30 min established earlier (see "Temperature effect on adsorption" section) was further collaborated by the fact that the first data point for all the plots correspond (approximately) to $30 \mathrm{~min}$. This also explains the progressive decrease in the rate constants $\left(k_{1}\right.$, $k_{2}$ and $k_{3}$ ) as the adsorption approaches equilibrium point. According to McKay et al. (1985), the inability of the plot lines of intra-particle diffusion model to go through the origin suggests the influence of other mechanisms asides intra-particle diffusion on such adsorption process. Hence, on the basis of the observation made from Fig. S4 (as none of the plots crossed the origin), it is obvious that the present adsorption system existed under the influence of multiple mechanism.

\section{Comparison of adsorbent sorption performance}

The comparison of adsorbent performance is an important aspect of adsorption study. However, an efficient and accurate adsorbent comparison must be executed under the same prevalent environmental conditions (like $\mathrm{pH}$, temperature and ionic strength) since isotherms could vary with such factors. In this study, adsorbent percentage removal, maximum adsorption capacity, $\mathrm{q}_{\max }$ (obtained from Langmuir plot) and the Langmuir constant $\left(b=1 / K_{L}\right)$ will be adopted as the comparison criteria. In order to make for effective comparison of the adsorption performance of LBM, AlLBM and Mn-LBM, reference was made to Fig. 1. Similarly, a plot of experimentally derived $q_{t}$ against $C_{t}$ on the 
Fig. 4 Plot of experimental $q_{\mathrm{e}}$ against $C_{\mathrm{e}}$

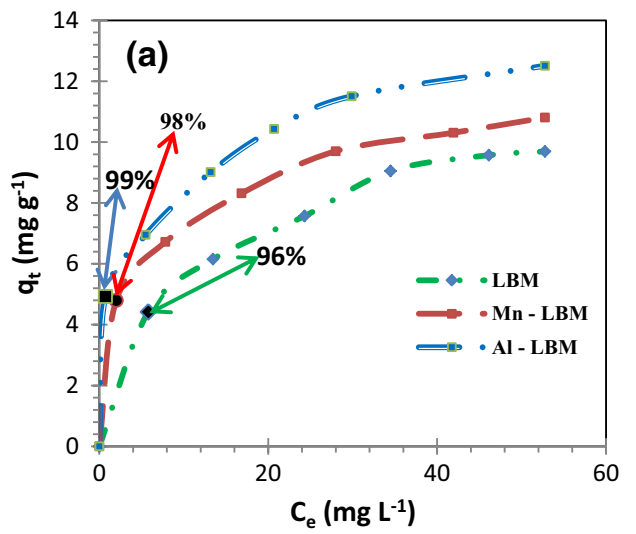

basis of the established optimum temperature $(343 \mathrm{~K})$ was generated (Fig. $4 \mathrm{a}, \mathrm{b})$, where $q_{t}\left(\mathrm{mg} \mathrm{g}^{-1}\right)$ and $C_{t}\left(\mathrm{mg} \mathrm{L}^{-1}\right)$ are the amount adsorbed and final adsorbate concentration, respectively, at a particular instant. The final adsorbate concentration $\left(C_{e}, \mathrm{mg} \mathrm{L}^{-1}\right)$ and calculated \% removal (Table S6) was deduced from the curve line for each adsorbent in Fig. 1.

From Fig. 4a, it could be observed that there exists six separate $q$ 's (adsorbed amount, $\mathrm{mg} \mathrm{g}^{-1}$ ) corresponding to six different percentage removal, thus recorded at time interval of $5 \mathrm{~min}$ until equilibrium was attained at $30 \mathrm{~min}$. However, available is only one point which represented the highest $\%$ removal at equilibrium for each adsorbent. On the basis of highest \% adsorbate removal (Fig. 4a), it could be concluded that the adsorbents performance follow the pattern: Al-LBM $>$ Mn-LBM > LBM. It is, however, worrisome that for each of the highest \% removal recorded for the three adsorbents, there exist a single (but numerically divergent) $C_{e}$ and $q_{e}$. Hence, such comparison is somewhat inaccurate, as it was not conducted on the same basis (that is same $C_{e}$ ). Therefore, in an attempt to ensure a more accurate performance comparison based on \% removal, the comparison was conducted along the same line of $C_{e}$ for all adsorbents (Fig. 4b). The result obtained still suggests the same performance pattern recorded early (Al-LBM $>M n-L B M>L B M)$. Although the use of \% removal as a comparison criterion for adsorbent performance remains the commonly reported approach in the literature, it must be noted that this approach is only adequate for quick and approximate comparison of adsorbents. This is because it does not give any information on the concentration range where the highest recorded $\%$ removal took place (Holan et al. 1993).

The three adsorbents were further compared on the basis of their respective maximum adsorption capacity $\left(q_{\max }\right)$ value which was calculated from the fitting of the experimental data to the Langmuir isotherm model. The $q_{\max }$ from Langmuir model was adopted since the model showed a relatively low $F_{\text {error }}$ value for all the adsorbents, an indication of good fit model. The Langmuir plot presented in Fig. 5a, $\mathrm{b}$ depicts the sorption performance of the adsorbents (based on $q_{\text {max }}$ ), where the independent variable in the system is the equilibrium concentration $\left(C_{\mathrm{e}}\right)$. It could be observed that the curve line of LBM at some point intersected with those of Al-LBM and Mn-LBM, while that of Al-LBM also intersected with that of Mn-LBM (Fig. 5). At such intersection point, the performance of those adsorbent in question are the same (in terms of $q$ ). Therefore, at $C_{\mathrm{e}}<10 \mathrm{mg} \mathrm{L}^{-1}$ (see line $\mathrm{AB}$ in Fig. 5a), the performance pattern of the adsorbents (based on $q$-value) was LBM $>$ Mn-LBM $>$ Al-LBM. This implies that LBM will be better than the rest of the adsorbents at a lower concentration range. Comparatively, when
Fig. 5 Plot of Langmuir $q_{\max }$ against $C_{\mathrm{e}}$

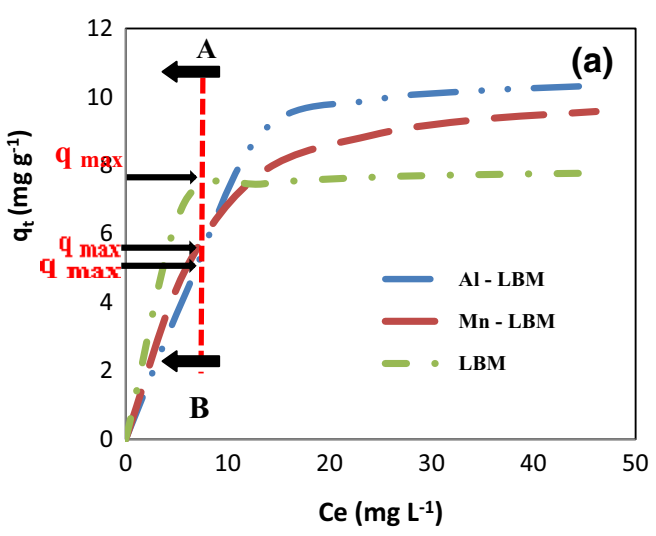


the adsorbent saturation is of uttermost importance; at higher adsorbate concentration range, the performance pattern will be Al-LBM > Mn-LBM > LBM (line AB in Fig. 5b).

Another important comparison criterion is the characteristics of the adsorption isotherm curve (initial slope). A curve with a steep slope indicates an adsorbent with high affinity for the adsorbate at low concentration range. This affinity is expressed as the Langmuir constant, $b\left(b=\frac{1}{K_{L}}\right)$; thus, the lower the $b$-value occasioned by a large $K_{L}$-value (Table S2 and Fig. 5), the higher the affinity. Based on this criterion, the adsorbent performance pattern is $\mathrm{LBM}>\mathrm{Mn}-\mathrm{LBM}>\mathrm{Al}-\mathrm{LBM}$.

\section{Thermodynamic studies}

The enthalpy $(\Delta H)$ and entropy $(\Delta S)$ values for the adsorption system were obtained from the slope and intercept of the linear plot of $\operatorname{Ln}(K)$ versus $T^{-1}$. Similarly, the $\Delta G$-values obtained at varying temperatures were calculated using Eq. S27. The thermodynamic parameters are presented in Table S7. The result showed that as the temperature increased (from 303 to $343 \mathrm{~K}$ ), the $\Delta G$-values became increasingly negative, a clear attestation to the feasible and spontaneous nature of the system. According to Yikia et al. (2013), on adsorption onto an adsorbents' surface, adsorbates often dissociate from their surrounding water molecules. This occurrence could be the probable explanation for the positive $\Delta S$-value obtained, thus revealing an increased disorderliness in the system. Similarly, the endothermicity of the present adsorption system was clearly demonstrated by the positive $\Delta H$-values of. Similar trend of result as those reported here was obtained by Menkiti and Aniagor (2017).

\section{Conclusion}

- LBM (bamboo-based lignin) was successfully synthesized from a simulated effluent of textile manufacturing process for bamboo fabrics. The LBM modified with $\mathrm{Al}^{3+}(\mathrm{Al}-\mathrm{LBM})$ and $\mathrm{Mn}^{2+}(\mathrm{Mn}-\mathrm{LBM})$ was efficient in adsorption of aqueous crystal violet dye (CVD).

- The FTIR and SEM results showed significant difference in the available functional groups and surface morphology, respectively, of the unmodified (LBM) and chemically modified (Al-LBM and Mn-LBM) adsorbents.

- For complete adsorption process, optimum contact time and temperature were determined.

- Langmuir, Sip and Freundlich isotherm models provided the best fit for LBM, Al-LBM and Mn-LBM, respectively, while first-order (PFO) model effectively predicted the kinetic data for the adsorbents. Using intra-particle diffusion model, it was established that the present adsorption system was characterized with multiple mechanisms.

- Similarly, the obtained entropy $(\Delta S)$, enthalpy $(\Delta H)$ and Gibbs free energy $(\Delta G)$ values confirmed the favorable, endothermic and spontaneous nature of the studied system.

- The comparison of adsorption performance reveals that LBM and Al-LBM will be most effective at lower and higher adsorbate concentration range, respectively.

\section{Compliance with ethical standards}

Conflict of interest On behalf of all authors, the corresponding author states that there is no conflict of interest.

Open Access This article is distributed under the terms of the Creative Commons Attribution 4.0 International License (http://creativeco mmons.org/licenses/by/4.0/), which permits unrestricted use, distribution, and reproduction in any medium, provided you give appropriate credit to the original author(s) and the source, provide a link to the Creative Commons license, and indicate if changes were made.

\section{References}

Adebayo MA, Prola LDT, Lima EC, Puchana-Rosero CR, Saucier C, Umpierres CS, Vaghetti CP, Da Silva LG, Ruggiero R (2014) Adsorption of procion blue MX-R dye from aqueous solutions by lignin chemically modified with aluminum and manganese. $\mathrm{J}$ Hazard Mater 268:43-50

Ameta KL, Malkania RK, Ameta SC (2010) Use of semiconducting manganese (IV) oxide particulate system as a photocatalyst: photo-assisted bleaching of some dyes. Int J Chem Sci 8(3): $1658-1668$

Aniagor CO, Menkiti MC (2018) Kinetics and mechanistic description of adsorptive uptake of crystal violet dye by lignified elephant grass complexed isolate. J Environ Chem Eng 6:2105-2118. https ://doi.org/10.1016/j.jece.2018.01.070

Bitenc M, Horvat B, Likozar B, Dražić G, Orel ZC (2013) The impact of $\mathrm{ZnO}$ load, stability and morphology on the kinetics of the photocatalytic degradation of caffeine and resazurin. Appl Catal B Environ 136:202-209

Cardoso NF, Lima EC, Royer B, Bach MV, Dotto GL, Pinto LAA, Calvete T (2012) Comparison of Spirulina platensis microalgae and commercial activated carbon as adsorbents for the removal of reactive red 120 dye from aqueous effluents. J Hazard Mater 241-242:146-153

Chen H (2014) Biotechnology of lignocellulose: theory and Practice. Springer, Dordrecht. https://doi.org/10.1007/978-94-007-6898-7-2

Elghniji K, Ksibi M, Elaloui E (2019) Sol-gel reverse micelle preparation and characterization of $\mathrm{N}$-doped $\mathrm{TiO}_{2}$ : efficient photocatalytic degradation of methylene blue in water under visible light. J Ind Eng Chem 72:178-182

Gao H, Kan T, Zhao S, Qian Y, Cheng X, Wu W, Wang X, Zheng L (2013) Removal of anionic azo dyes from aqueous solution by functional ionic liquid cross-linked polymer. J Hazard Mater 261:83-90 
Günter G, David SM (2014). Handbook of spectroscopy, 2nd edn. Wiley, New York. ISBN: 9783527321506, https://doi. org/10.1002/9783527654703

Holan ZR, Volesky B, Prasetyo I (1993) Biosorption of Cd by biomass of marine algae. Biotechnol Bioeng 41:819-825

Jaime LC, Dalia IS, Reyna GS, Ma AC (2017) Study of a fixed-bed column in the adsorption of an azo dye from an aqueous medium using a chitosan-glutaraldehyde biosorbent. Adsorp Sci Technol 36(1):1-18. https://doi.org/10.1177/0263617416688021

Kannan C, Muthuraja K, Devi MR (2013) Hazardous dyes removal from aqueous solution over mesoporous aluminophosphate with textural porosity by adsorption. J Hazard Mater 244-245:10-20

Mckay G, Otterburn MS, Aga DA (1985) Fullers earth and fired clay as adsorbent for dye stuffs, equilibrium and rate constants. Water Air Soil Pollut 24:307-322

Menkiti MC, Aniagor CO (2017) Parametric studies on descriptive isotherms for the uptake of crystal violet dye from aqueous solution onto lignin-rich adsorbent. Arab J Sci Eng. https://doi. org/10.1007/s13369-017-2789-3

Menkiti MC, Ejiofor M, Ezemagu I, Uddameri V (2015) Turbid-metric approach on the study of adsorptive component of paint effluent coagulation using snail shell extract. Arab J Sci Eng 2(1):23-29

Menkiti MC, Ejimofor MI, Ezemagu IG, Uddameri V (2016) Turbidmetric approach on the study of the adsorptive component of paint effluent coagulation using snail shell extract. Arab J Sci Eng 41:2527. https://doi.org/10.1007/s13369-015-2013-2

Menkiti MC, Abonyi MN, Aniagor CO (2018a) Process equilibrium, kinetics and mechanisms of ionic-liquid induced dephenolation of petroleum effluent. Water Conserv Sci Eng 1:11. https://doi. org/10.1007/s41101-018-0052-8

Menkiti MC, Aniagor CO, Agu CM, Ugonabo VI (2018b) Effective adsorption of crystal violet dye from an aqueous solution using lignin-rich isolate from elephant grass. Water Conserv Sci Eng 3(1):33-46. https://doi.org/10.1007/s41101-017-0040-4

Michael S (2007) Bamboo, bamboo clothing, bamboo fabric, bamboo manufacturing, bamboo rayon. Retrieved from http://organ icclothing.blogs.com/my_weblog/2007/09/bamboo-facts-be.html. Accessed 5 Jan 2019

Nethaji S, Sivasaoyyy A, Mandal S (2013) Preparation and characterization of corn cob activated carbon coated with nano-sized magnetite particles for the removal of $\mathrm{Cr}(\mathrm{VI})$. Bioresour Technol 134:94-100

Ngah WSW, Teong LC, Hanafiah MAKM (2011) Adsorption of dye and heavy metal ions by chitosan composites: a review. Carbohydr Polym 83:1446-1456

Oladoja NA, Aboluwoye CO, Oladimeji YB, Ashogbon AO, Otemuyiwa IO (2008) Studies on castor seed shell as a sorbent in basic dye contaminated wastewater remediation. Desalination 227:190-203

Osol A, Hoover JE (eds) (1975) Remington's pharmaceutical sciences, 15th edn. Mack Publishing Co., Easton, p 1091

Ruggiero R, Machado AEH, Gardrat C, Hoareau W, Grelier S, Siegmund B, Castellan A (2005) Photodegradation of sugar cane bagasse acidolysis lignins. J Photochem Photobiol 173:150-155
Srivastava M, Begovic E, Chapman J, Putnam NH, Hellsten U, Kawashima T, Kuo A, Mitros T, Salamov A, Carpenter ML, Signorovitch AY, Moreno MA, Kamm K, Grimwood J, Schmutz J, Shapiro H, Grigoriev IV, Buss LW, Schierwater B, Dellaporta SL, Rokhsar DS (2008) The Trichoplax genome and the nature of placozoans. Nature 454:955-960. https://doi.org/10.1038/natur e07191

Suhadolnik L, Pohar A, Likozar B, Čeh M (2016) Mechanism and kinetics of phenol photocatalytic, electrocatalytic and photoelectrocatalytic degradation in a $\mathrm{TiO}_{2}$-nanotube fixed-bed microreactor. Chem Eng J 303:292-301

Vargas MM, Almeida VC, Andre LC, Martins AC, Morqes JC, Garcia EE, Guaze GF, Costa WF (2012) Kinetics and equilibrium studies: adsorption of food dyes acid yellow 6, acid yellow 23 and acid red 18 on activated carbon from flambouyant pods. Chem Eng J 32(181-182):243-250

Villarreal IAA, Montoya LAR, Montoya VH, Petriciolet AB, Morán MAM, López EMR (2013) Sorption mechanism of anionic dyes on pecan nut shells (Carya illinoinensis) using batch and continuous systems. Ind Crops Prod 48:89-97

Yikia Y, Bo X, Yijiu J, Qian J (2013) Preparation and adsorption properties of diethylenetriamine-modified Chitosan beads for acid dyes. J Appl Polym Sci 130:4090-4098

Yin P, Wang Y, Li Y, Deng C, Zhang X, Yang P (2012) Preparation of sandwich-structured graphene/mesoporous silica composites with C8-modified pore wall for highly efficient selective enrichment of endogenous peptides for mass spectrometry analysis. Proteomics 12(18):2784-2791. https://doi.org/10.1002/pmic.201200116

Yinliang L, Miao W, Bo W, Yuying W, Mingguo M, Xueming Z (2016) Synthesis of magnetic lignin-based hollow microspheres: a highly adsorptive and reusable adsorbent derived from renewable resources. ACS Sustain Chem Eng 4(10):5523-5532. https ://doi.org/10.1021/acssuschemeng.6b01244

Yu Y, Murthy BN, Shapter JG, Constantopoulos KT, Voelcker NH, Ellis AV (2013) Benzene carboxylic acid derivatized graphene oxide nanosheets on natural zeolites as effective adsorbents for cationic dye removal. J Hazard Mater 260:330-338

Zhao XT, Zeng T, Hu ZJ, Gao HW, Zou CY (2012) Modeling and mechanism of the adsorption of proton onto natural bamboo sawdust. Carbohydr Polym 87:1199-1205

Zhingang J, Ziyu L, Tao N, Shengbiao L (2017) Adsorption of lowcost absorption materials based on biomass (Cortaderia selloana flower spikes) for dye removal: kinetics, isotherms and thermodynamic studies. J Mol Liq 229:285-292

Publisher's Note Springer Nature remains neutral with regard to jurisdictional claims in published maps and institutional affiliations. 